\title{
Prospective comparative study of computer programs used for management of warfarin
}

\author{
L Poller, D Wright, $M$ Rowlands
}

\begin{abstract}
Aims-To compare the effectiveness of three computerised systems that are currently used for assisting warfarin control in outpatients with the customary dosing method used by experienced medical staff. Methods-A pilot randomised study of three systems with a follow up independently randomised study of two of these was made on 186 patients receiving long term treatment or who had recently started warfarin treatment and had been discharged from hospital.

Results-All three computerised systems seemed to give satisfactory control compared with the traditional dosing method. For patients receiving more intensive treatment with an assigned target range of $3 \cdot 0-4 \cdot 5$ computerised dosage programs achieved significantly better control; the medical staff undertreated such patients almost $50 \%$ of the time.

Conclusion-Computer based programs can assist outpatient anticoagulant control with warfarin during both early and long term treatment. For most patients the control achieved is as good as that obtained by the customary method of dosing, by experienced clinic doctors, although the latter tend to be too conservative when dosing patients within the intense target range of 3.0 to 4.5 International Normalised Ratio (INR). The computers were significantly more successful in this higher range.
\end{abstract}

(F Clin Pathol 1993;46:299-303)

Warfarin and other related oral anticoagulant drugs are widely prescribed in hospital practice for a variety of clinical disorders. Monitoring the patient's prothrombin time response to these drugs on the basis of the International Normalised Ratio (INR), and adjustment of the dose to achieve a target INR range, is costly in terms of medical and administrative time.

The degree of anticoagulant control achieved varies considerably between centres.

Keference Anticoagulant

Reagents and Control, Withington Hospital, Manchester M20 8LR L Poller

D Wright

$M$ Rowlands

Correspondence to:

Professor L Poller

Accepted for publication

7 October 1992 Previous surveys have found that patients are adequately anticoagulated from $50-85 \%$ of the time. ${ }^{12}$

There has been increasing interest in the value of computer-based dosage programs to assist in the control of outpatients receiving warfarin treatment. The observations from earlier studies suggest that such programs may assist and improve control of long term warfarin treatment. ${ }^{3-5}$ They also seem to reduce demands on medical and secretarial time.

At present there is little experience with such programs during the early stage of warfarin treatment which follows discharge from hospital. There are also no comparative data on the efficacy of the various systems or controlled studies of their reliability in dosing compared with the traditional method.

The aim of the present controlled study was to determine the feasibility of computerised dosing during this critical early phase. We also undertook to compare its effectiveness with the customary dosing method for patients during long term warfarin and those recently started on treatment. We confined this study to the assessment of the degree of control of dosage achieved by the systems. We have not attempted to evaluate their additional functions which include audit and clinic administration.

\section{Methods}

The customary method of dosing by experienced medical staff in an anticoagulant clinic was studied alongside the following three computerised dosage programs:

1 the Hillingdon system AC version $3 \cdot 1-a$ model derived from that used at both Hillingdon $^{3}$ and Chesterfield ${ }^{4}$ to control warfarin treatment in outpatients.

2 the Charles Anticoagulant Clinic Manager-a system used in the Department of Haematology, St Thomas's Hospital, London, to assist management of the anticoagulant clinic-all suggestions generated by this program are subject to medical review;

3 the Coventry program-which has been considered to be effective in improving anticoagulant control in South Warwickshire. ${ }^{5}$

On discharge from this hospital all patients who have recently started treatment with warfarin are referred to one of the anticoagulant clinics conducted by the Haematology Department at Withington Hospital. Between November 1990 and June 1991 all such new patients were entered into the study.

Before their first clinic attendance each four ways-that is, one of the three computerised dosage systems or by the medical staff.

After an interim assessment use of the Hillingdon system was suspended and a further period of randomisation occurred. From October 1991 to April 1992 all new patients 
Table 1 Clinical diagnoses of patients dosed by each method

\begin{tabular}{lccccc}
\hline & $\begin{array}{l}\text { Customary } \\
\text { dosing }\end{array}$ & $\begin{array}{l}\text { Charles } \\
\text { system }\end{array}$ & $\begin{array}{l}\text { Coventry } \\
\text { system }\end{array}$ & $\begin{array}{l}\text { Hillingdon } \\
\text { system }\end{array}$ & Total \\
\hline Venous thrombo-embolism & 24 & 24 & 19 & 7 & 74 \\
Arterial disease & 20 & 18 & 14 & 4 & 56 \\
Lone atrial fibrillation & 6 & 5 & 12 & 0 & 23 \\
Rheumatic heart disease & 7 & 3 & 5 & 0 & 15 \\
Cerebrovascular disease & 3 & 3 & 3 & 1 & 10 \\
Others & 4 & 4 & 0 & 0 & 8 \\
Total & 64 & 57 & 53 & 12 & 186 \\
\hline
\end{tabular}

were again entered into the study. A group of 58 patients who had been receiving warfarin for over six months were also included in the study. These patients were randomised to dosage by one of the three remaining methods-the Charles system, Coventry program, or the traditional dosing method by the clinic doctors.

Each new patient on his/her first visit to the outpatient clinic received an explanation of the aims of warfarin treatment and was counselled with regard to possible side effects by one of the authors (LP). The following details were obtained from the patients' records: age and sex; diagnosis; concurrent medication. This information, in conjunction with the revised British Society for Haematology (BSH) guidelines on oral anticoagulation, ${ }^{6}$ was used to assign an INR target range (either $2 \cdot 0-3 \cdot 0$ or $3 \cdot 0-4 \cdot 5$ ) for each patient.

Patients randomised to the customary dosing method were reviewed on each occasion by any one of four doctors who normally supervise the dosage in the clinic. More than one doctor was therefore responsible for the customary clinic dosage of each patient. The dose of warfarin was based on the INR result of a capillary prothrombin test performed immediately before the interview with the doctor. The doctors performing the customary clinic dosing were not aware whether an individual patient had been randomised into the study.

Patients randomised to one of the computer systems had their INR values entered into the appropriate program. The system then suggested a dose of warfarin, the interval to the next clinic visit, and in cases of over-anticoagulation possible suspension of warfarin treatment for a variable number of days. All advice was reviewed before being passed on to the patient by a doctor. If the advice on dosage and interval to next outpatient attendance was considered by one of us (MR or DW) to be so inappropriate that it might harm the patient, confirmation by a second medical opinion was sought. At each subsequent visit a similar procedure was followed.

The Hillingdon and Charles programs allow the user to vary certain options which modify the dosage and interval suggestions generated by the algorithms of the two systems. An upper limit of eight weeks for the time interval between visits was chosen as this is the maximum permitted interval for our customary clinic practice. Other options were open to change. For the purpose of this study, however, we accepted those recommended by the respective programs. For the Hillingdon program this included a dose adjustment coefficient of 0.58 and a dose adjustment figure of 0.8 for high INR values, and a multiplication factor of 0.35 for the Charles program. No such options are available for use with the Coventry program which allows a maximum clinic interval of 12 weeks, though for the duration of our study no interval longer than eight weeks was suggested. For every visit the following was recorded: INR; suggested dose and interval; any alteration to the computer generated advice; any clinical events.

The results were converted to dichotomies, dependent on whether the INR value at each visit was in the required range (success) or outside (failure). $\chi^{2}$ analysis was then performed and significance was set at the conventional 5\% level. All computations were carried out using the GLIM 3.77 computer package.

\section{Results}

Five hundred and seventy five dosings were performed on the 186 patients. Sixty four patients (36 male, 28 female) were randomised to receive dose prescription by the medical staff; the age range of these was 24-92 years (mean 65.7 years). Fifty seven patients ( 31 male, 26 female) were allocated to the Charles programme, age range $31-90$ years (mean 63.8 years); 53 patients to the Coventry system (32 male, 21 female), age range 35-99 years (mean 64.8 years); and another 12 patients (eight male, four female) to the Hillingdon system, age range 29-75 years (mean 61.2 years). The clinical diagnoses prompting anticoagulation were similar for the four methods of control (table 1). The concurrent medication taken by each group was also similar (data not shown). One hundred and twenty eight of the patients recruited had recently begun treatment, 58 were receiving long term treatment. These groups were similar with respect to age and gender mix, although inevitably there were differences in the spread of clinical diagnoses. Proportionately there were more cases of venous thrombosis in the new patient group

Table 2 Results of customary $v$ computer dosing of anticoagulants (percentage values in parentheses)

\begin{tabular}{|c|c|c|c|c|c|c|c|c|}
\hline & $\begin{array}{l}\text { No of } \\
\text { patients }\end{array}$ & $\begin{array}{l}\text { No of } \\
\text { dosings } \\
\text { performed }\end{array}$ & $\begin{array}{l}\text { No of visits } \\
\text { patients } \\
\text { over } \\
\text { anticoagulated }\end{array}$ & $\begin{array}{l}\text { No of visits } \\
\text { patients } \\
\text { under } \\
\text { anticoagulated }\end{array}$ & $\begin{array}{l}\text { No of visits } \\
\text { in range }\end{array}$ & $\begin{array}{l}\text { No of times } \\
\text { computer } \\
\text { dose } \\
\text { amended }\end{array}$ & $\begin{array}{l}\text { No of times } \\
\text { computer } \\
\text { interval } \\
\text { reduced }\end{array}$ & $\begin{array}{l}\text { Mean time } \\
\text { interval } \\
\text { (weeks) }\end{array}$ \\
\hline Customary dosing & 64 & 234 & $41(17 \cdot 5)$ & $75(32 \cdot 1)$ & $118(50 \cdot 4)$ & - & - & $3 \cdot 1$ \\
\hline Charles system & 57 & 170 & $27(15.9)$ & $47(27 \cdot 6)$ & $96(56.5)$ & 0 & $3(1 \cdot 8)$ & $2 \cdot 9$ \\
\hline Coventry system & 53 & 128 & $28(21 \cdot 9)$ & $32(25)$ & $68(53 \cdot 1)$ & & $10(7 \cdot 8)$ & $3 \cdot 2$ \\
\hline Hillingdon program & 12 & 43 & $4(9 \cdot 3)$ & $15(34.9)$ & $24(55 \cdot 8)$ & $2(4 \cdot 7)$ & $3(7 \cdot 0)$ & $2 \cdot 1$ \\
\hline
\end{tabular}


Table 3 Percentage of visits spent in various INR bands for customary and computer dosed patients

\begin{tabular}{lllll}
\hline & $\begin{array}{l}\text { INR of } \\
<2 \cdot 0\end{array}$ & $\begin{array}{l}\text { INR } \\
2 \cdot 0-4 \cdot 0\end{array}$ & $\begin{array}{l}\text { INR } \\
2 \cdot 0-4 \cdot 5\end{array}$ & $\begin{array}{l}\text { INR of } \\
>4 \cdot 5\end{array}$ \\
\hline Traditional dosing & $17 \cdot 7$ & $69 \cdot 6$ & $74 \cdot 0$ & $8 \cdot 1$ \\
Charles system & $15 \cdot 3$ & $68 \cdot 2$ & $75 \cdot 9$ & $8 \cdot 8$ \\
Coventry system & $22 \cdot 7$ & $68 \cdot 8$ & $71 \cdot 7$ & $6 \cdot 3$ \\
Hillingdon system & $23 \cdot 3$ & $74 \cdot 4$ & $74 \cdot 4$ & $2 \cdot 3$ \\
\hline
\end{tabular}

and more cases of atrial fibrilation, with or without rheumatic heart disease, in the long term group.

No significant differences were found between the results obtained from the two periods of randomisation, and therefore the data from the two studies were combined into a single analysis. The number of readings available with the Hillingdon system was too small to allow significant differences to be established between it and the other three methods.

The results obtained with the four methods are compared in table 2 . Dosing by the clinic doctors maintained patients' INR values within the target range on $50.4 \%$ of visits whereas the respective figures for the Charles, Coventry, and Hillingdon programs were $56.5 \%, 53.1 \%$, and $55.8 \%$ of visits. Overall, there was no significant difference in the control achieved by the four methods $\left(\chi^{2}\right.$ $3=2.05 ; p=0.57)$. The computer generated time interval to the next visit was reduced on 16 occasions: by $1.8 \%$ in the case of the Charles system and $7 \cdot 8 \%$ for the Coventry program. Advice generated by the Hillingdon system required amendment on $11.7 \%$ of visits which included two dosage adjustments. Dosing by all four methods was more likely to lead to undertreatment than overtreatment (INR values below rather than above the INR target range). The mean time interval between visits was similar for customary dosing, the Charles, and the Coventry systems. For the Hillingdon program, more frequent visits resulted (table 2 ).

Table 3 gives the time spent by patients with INR values in the range of $2 \cdot 0-4 \cdot 5$. This band has previously been felt to reflect satisfactory anticoagulant control and has been used for auditing purposes in our clinic for many years. Patients dosed by the clinic doctors were maintained in this broader range on $74 \%$ of visits, with similar figures for the individual computer systems.

Separation of the data obtained with short and long term warfarin treatment is shown in table 4. No significant difference emerged in
Table 5 Results obtained from patients with assigned INR ranges $2 \cdot 0-3 \cdot 0$ or $3 \cdot 0-4 \cdot 5$

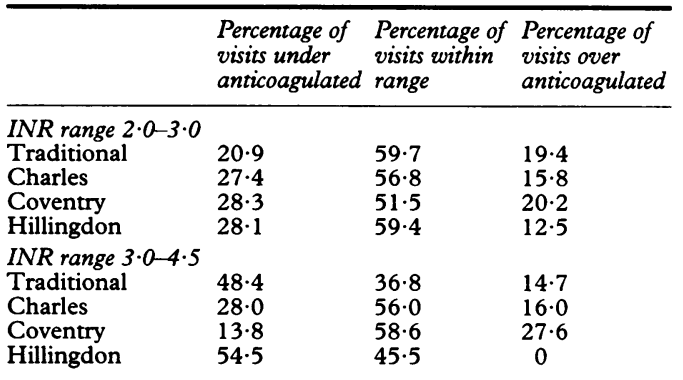

the control achieved by the various methods. For patients receiving long term treatment both the clinic doctors and the Coventry program were almost twice as likely to overdose the patients than to underdose them. The Coventry system produced the longest interval between clinic visits for new patients but the shortest interval for those receiving long term treatment.

When the results were analysed with respect to the two target ranges differences became apparent (table 5). For patients assigned a $3 \cdot 0-4 \cdot 5$ target band, computerised dosing was more effective in maintaining the INR within range (on $56.0 \%$ and $58.6 \%$ of visits for the Charles and Coventry systems, respectively) than traditional dosing $(36.8 \%$ of visits). This achieved significance $\left(\chi^{2}\right.$ (3) $=8.05 ; \mathrm{p}=0.044)$. For the last group patients were underanticoagulated on $48.4 \%$ of visits. The improved control obtained with the Hillingdon system was not as pronounced $(45.5 \%$ of visits within range). Patients assigned this higher range and dosed by the Coventry system were almost twice as likely to be overanticoagulated than by any of the other methods.

For the $2 \cdot 0-3 \cdot 0$ range patients dosed using the traditional method seemed to be slightly better-INR values within range on $59.7 \%$ of visits, followed by the Hillingdon system $59.4 \%$, the Charles at $56 \cdot 8 \%$, and Coventry at $51.5 \%$, but the differences were not significant $\left(\chi^{2}(3)=1 \cdot 79 ; p=0.62\right)$. For the less intense range all methods, including the Coventry, were more likely to undertreat than overtreat patients.

One patient dosed by the Coventry system died while in the study. His INR values were within the target range to the time of death. No episodes of major bleeding occurred and no other important clinical events were recorded.

\section{Discussion}

Previous reports of outpatient anticoagulation practice have found that patients are only adequately anticoagulated $50 \%$ to $85 \%$ of the time. ${ }^{2}$ The results obtained with our traditional dosing method by the medical staff on the basis of INR values being within the desired range on $50.4 \%$ of visits are similar to those of an earlier survey. ${ }^{1}$ Our strict use of the segmented therapeutic ranges defined by the British Society for Haematology makes
Charles

Coventry

Hillingdon

$29 \cdot 0$

$29 \cdot 6$
$34 \cdot 9$

$50 \cdot 8$
$55 \cdot 7$

$54 \cdot 3$
$55 \cdot 8$

$15 \cdot 3$

$16 \cdot 0$
$9 \cdot 3$

$2 \cdot 6$
$3 \cdot 1$

$3 \cdot 1$
$2 \cdot 1$

Long term warf

$18 \cdot 9$

Charles

49.1

$59 \cdot 0$
$51 \cdot 1$

$32 \cdot 1$
$17 \cdot 9$

17.9
31.9

$4 \cdot 9$

$3 \cdot 9$
$3 \cdot 4$ 
for unfair comparison with studies that have used the previously advocated wider British Corrected Ratio (BCR) range of $2 \cdot 0-4 \cdot 0 .{ }^{7}$ Taking an INR range of $2 \cdot 0-4 \cdot 5$ to define satisfactory anticoagulation, our traditionally dosed patients were adequately treated on $74 \%$ of visits. This is similar to the figure of $75.7 \%$ for patients attending our anticoagulant clinics over the past six years and compares favourably with the results of earlier studies.

For those patients dosed by any of the three computer systems the control achieved was very close to that obtained with experienced medical staff dosing. Use of the Charles system at St Thomas's also failed to demonstrate any major improvement in anticoagulant control. ${ }^{8}$ Our finding that on $56.5 \%$ of visits patients dosed by Charles method had INR values within range, is remarkably close to the figure of $55 \%$ achieved there.

Earlier reports on the use of the Hillingdon program indicated much better control than we have observed. ${ }^{349}$ Our inclusion of early warfarin control and the use of narrower therapeutic INR intervals to define satisfactory control would presumably largely account for the difference. After the first period of randomisation use of the Hillingdon program was discontinued because of the increased need to amend dosage and interval suggestions $(11.7 \%$ of visits) compared with the other systems. Operating the program also proved relatively cumbersome and it resulted in patients attending more frequently than did use of the other methods. Consequently the total number of dosings obtained with the Hillingdon program is comparatively small, making it difficult to draw any firm conclusions about its efficacy, particularly when analysing subgroups of patients.

Adoption of the Coventry program in South Warwickshire has resulted in a progressive increase in the proportion of patients with INRs within the therapeutic range, from $45.3 \%$ to $62.9 \%$, over a six month period. ${ }^{5}$ The data presented in that study, however, were confined to those patients assigned a target range of $3 \cdot 0-4 \cdot 5$. For this subgroup we also observed significantly better control with the Coventry system (58.6\% of visits in range compared with $36 \cdot 8 \%$ for traditional dosing). It is of concern, however, that for those more intensely treated patients use of the Coventry program resulted in their INR values being greater than 4.5 on more than a quarter of visits. The Charles system also performed favourably within this group (INR in range on $56.0 \%$ of visits). Medical staff seem to be overly cautious when dosing patients within the higher target range, such that these patients remained undertreated almost $50 \%$ of the time.

The alteration in diet and lifestyle associated with discharge from hospital make warfarin requirements unstable at that time. Copplestone and Roath ${ }^{2}$ found that during the initial three months of treatment patients were adequately anticoagulated $69 \%$ of the time compared with $88 \%$ of the time for patients running long term anticoagulation (using a BCR range of $2 \cdot 0-4 \cdot 0$ ). In contrast, we found that customary dosing and dosing by the Conventry system achieved slightly better control in patients who had recently started treatment than for those receiving long term treatment, although the difference was not significant.

The finding that advice generated by computer systems needed alteration on only $3 \cdot 1 \%$ of visits was unexpected. Use of the Charles system at St Thomas's had found that $20 \%$ of decisions required amendment (unpublished data) compared with just $1.8 \%$ in our study.

We have shown that computerised dosage programs can reliably assist anticoagulant control during both early and long term warfarin treatment; less than $4 \%$ of generated advice needed revision. However, overall control achieved is comparable with, but no better than, that obtained with the customary method of dosing by experienced medical staff.

Varying levels of computer involvement in outpatient warfarin management can be envisaged:

1 to conduct the anticoagulant clinic on traditional lines-all dosing performed manually with record keeping by hand;

2 to use the computer to monitor the audit and administrative aspects of the clinic only. All dosing to be carried out by medical staff;

3 to conduct the medical staff interview and dosing of patients with a lap-top computer system available in the clinic to provide dose suggestions to assist the clinician;

4 to allow the computer to prescribe for patients with stable dose requirements, leaving medical staff to concentrate on improving the control of the minority of patients with poor compliance, etc;

5 to fully computerise the clinic, so that at their attendance patients simply give a blood sample. The warfarin dose is computer generated and sent to the patient by post. No medical contact is required with this option.

Neither options 1 or 5 seem to be the best because of practical and safety considerations, respectively. Of the remaining three possibilities, each centre running an anticoagulant clinic should adopt the one which best fits with local requirements. For those hospitals with sufficient clinic accommodation, time, and experienced staff option 2 seems to be reasonable. When newly appointed staff are participating in the clinic then option 3 would allow the inexperienced doctor to gain confidence with dosing by having a second opinion in the clinic room alongside him or her. In centres where clinic space is restricted or absent and dosing is performed by junior house staff rushing off to deal with more pressing medical problems then option 4 may be preferred.

To conclude, where experienced medical staff participate in well run clinics, dosing in 
the traditional manner, computer dosage systems should not be expected to improve anticoagulant control within the lower INR range of 2 to 3. They might, however, still be considered for their other advantages in documentation and administration.

We thank Drs G Weston Smith, PE Rose, and AH James for advice on the respective computer systems.

1 Duxbury B McD. Therapeutic control of anticoagulant treatment. Br Med $₹$ 1982;284:702-4.

2 Copplestone A, Roath S. Assessment of therapeutic control of anticoagulation. Acta Haematol 1984;71:376-80.
3 Wilson R, James AH. Computer assisted management of warfarin treatment. Br Med $\mathcal{f} 1984 ; 289: 422-4$.

4 Wyld PJ, West D, Wilson TH. Computer dosing in anticoagulant clinics-the way forward? Clin Lab Haematol 1988;10:235-6.

5 Ryan PJ, Gilbert M, Rose PE. Computer control of anticoagulant dose for therapeutic management. $\mathrm{Br} \mathrm{Med} f$ 1989;299:1207-9.

6 British Society for Haematology. Guidelines on oral anticoagulation: Second edition. F Clin Pathol 1990;43: 177-83.

7 Blackburn EK. Long term anticoagulant therapy. Prescribers fournal 1977;17:73-4.

8 Weston Smith SG, Savidge GF. Computer control of anticoagulant dose. Br Med $\mathcal{f}$ 1989;299:1529.

9 Kubie A, James AH, Timms J, Britt RP. Experience with a computer assisted anticoagulant clinic. Clin Lab Haematol 1989;11:385-91. 